\title{
Review Article \\ What Is Known about Elementary Grades Mathematical Modelling
}

\author{
Micah S. Stohlmann ${ }^{1}$ and Lluís Albarracín ${ }^{2}$ \\ ${ }^{1}$ University of Nevada, Las Vegas, NV 89154, USA \\ ${ }^{2}$ Universitat Autònoma de Barcelona, Cerdanyola del Valles 08193, Spain \\ Correspondence should be addressed to Micah S. Stohlmann; micah.stohlmann@unlv.edu
}

Received 11 April 2016; Revised 24 May 2016; Accepted 5 June 2016

Academic Editor: Shu-Sheng Liaw

Copyright (C) 2016 M. S. Stohlmann and L. Albarracín. This is an open access article distributed under the Creative Commons Attribution License, which permits unrestricted use, distribution, and reproduction in any medium, provided the original work is properly cited.

\begin{abstract}
Mathematical modelling has often been emphasized at the secondary level, but more research is needed at the elementary level. This paper serves to summarize what is known about elementary mathematical modelling to guide future research. A targeted and general literature search was conducted and studies were summarized based on five categories: content of mathematical modelling intervention, assessment data collected, unit of analysis studied, population, and effectiveness. It was found that there were three main units of analysis into which the studies could be categorized: representational and conceptual competence, models created, and student beliefs. The main findings from each of these units of analysis are discussed along with future research that is needed.
\end{abstract}

\section{Introduction}

Mathematical modelling has mainly been emphasized at the secondary level, but for students to become more adept modellers the elementary grades need to be given more attention. We know that mathematical modelling abilities improve over time [1]. It then makes sense then to start mathematical modelling at earlier ages. There are many benefits to mathematical modelling that elementary students are missing if they are unable to participate in mathematical modelling: developing mathematical understandings $[2,3]$, coming to appreciate mathematics more and see it as more real life and applicable $[4,5]$, and developing communication and life skills [6].

At the elementary level, real world mathematics problems are often traditional word problems where teachers may instruct students on finding key words. Students come to believe that they should identify the numbers in the problem and do some operations with these numbers $[7,8]$. For example, a study that was done in the elementary grades involved telling students this story: "Mr. Lorenz and three colleagues started at Bielefeld at 9 AM and drove the 360 kilometers to Frankfurt with a rest stop of 30 minutes." There is no question, it is just a story. The story was told to kindergartners and they just say, "Thank you for the story."
The story was told to first graders and a few of them combine the numbers to get an answer. The story was then told to 2nd graders all the way up to 6th graders. Every year, more students than the previous grade level combine numbers and give an answer [9].

We want students to have the opposite effect, where each year they become more adept at reasoning with real world situations. If mathematical modelling is integrated more in the elementary grades students will be more used to situations that can be solved, making assumptions and approximations and identifying which is the most important information in a problem and what more information needs to be known. There is good work being done in the elementary grades in mathematical modelling, but more can be done in conducting research with this age group. This paper describes what is known about mathematical modelling at the elementary grade level (age 10 and under) in order that future research can be identified and situated in this literature.

\section{Essential Elements of Mathematical Modelling}

Our definition of mathematical modelling is an iterative process that involves open-ended, real world, practical problems 
TABLE 1: Principles for guiding MEA development.

\begin{tabular}{ll}
\hline Principle & Description \\
\hline Model construction & $\begin{array}{l}\text { Ensures that the activity requires the construction of an explicit description, explanation, or procedure } \\
\text { for a mathematically significant situation }\end{array}$ \\
\hline Generalizability & $\begin{array}{l}\text { Also known as the Model Shareability and Reusability Principle. Requires students to produce solutions } \\
\text { that are shareable with others and modifiable for other closely related situations }\end{array}$ \\
\hline Model documentation & $\begin{array}{l}\text { Ensures that the students are required to create some form of documentation that will reveal explicitly } \\
\text { how they are thinking about the problem situation }\end{array}$ \\
\hline Reality & $\begin{array}{l}\text { Requires the activity to be posed in a realistic context and to be designed so that the students can } \\
\text { interpret the activity meaningfully from their different levels of mathematical ability and general } \\
\text { knowledge }\end{array}$ \\
\hline Self-assessment & $\begin{array}{l}\text { Ensures that the activity contains criteria the students can identify and use to test and revise their current } \\
\text { ways of thinking }\end{array}$ \\
\hline Effective prototype & $\begin{array}{l}\text { Ensures that the model produced will be as simple as possible, yet still mathematically significant for } \\
\text { learning purposes (i.e., a learning prototype or a "big idea" in mathematics) }\end{array}$ \\
\hline
\end{tabular}

See [14].

that students make sense of with mathematics using assumptions, approximations, and multiple representations. Other sources of knowledge besides mathematics can be used as well. Mathematical modelling curricula should have multiple acceptable models that can be developed.

Mathematical modelling begins with a key question that stems from the real world problem. A key question can guide the solution and work of a mathematical modelling activity. An example of a key question is how big is someone based on his or her footprint and stride length? [10] A key question can serve in focusing on work and is often the way that people approach problems in their jobs.

Both clear verbal and written communication are paramount while students work on a mathematical modelling task and detail their solution. Students must also reflect on the modelling process in order to make explicit the mathematics that they used and how well they understood it. In addition, modelling activities should also be open-ended [11].

A modelling cycle (Figure 1) that appears often in the literature is from Blum and LeiB [12] and connects to several of our essential elements. There is a distinction between the real world and mathematics. It can be seen that students must make sense of the problem with mathematics involving assumptions and approximations, often called mathematizing, and then ensure that the model developed makes sense in the realistic context. Though not shown in the cycle it is well known that the modelling process is iterative in nature [13].

In summary, there are seven essential elements of mathematical modelling: (a) starting with a real world problem, (b) working from key questions, (c) making sense of the problem with mathematics often involving assumptions and approximations, (d) ensuring that the mathematics is accurate and makes sense in the realistic situation, (e) goal of clear verbal and written communication throughout that often includes multiple representations, (f) modelling that is an iterative process involving open-ended problems, and (g) reflection on mathematics used or the modelling process. All of these ideas are included in one mathematical modelling activity that appeared frequently in the articles in this paper: ModelEliciting Activities.

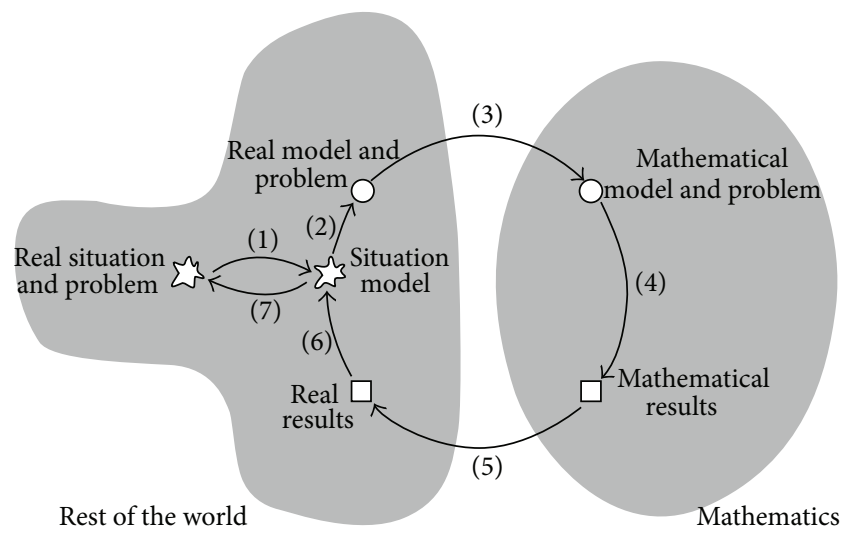

Figure 1: Blum and LeiB [12] modelling cycle.

2.1. Model-Eliciting Activities (MEAs). MEAs are clientdriven, open-ended, realistic problems that are developed based on six principles (Table 1). Often while completing an MEA, students will refine, revise, and extend powerful mathematics constructs [10]. MEAs are implemented starting with an opening article or video and then readiness questions to help students become familiar with the real world context and the problem statement. Next students work in groups to solve the problem. They then present their ideas to the whole class. Finally, in their small groups, they are given time for revision of their models and for reflection.

\section{Methods}

The results of this paper stem from a literature search for studies in the elementary grades on mathematical modelling (age 10 and under). Bryman [15] describes three central features of any quality literature review: (1) identifying adequate papers, (2) categorizing the papers, and (3) extended analysis including identifying areas of further research. First adequate papers were identified through a targeted and a general literature search. The targeted literature search involved looking 
TABLE 2: Summary of location of identified publications from literature search.

\begin{tabular}{lc}
\hline Journal, book, or conference & Number of publications \\
\hline International Community of Teachers of Mathematical Modelling and Applications (ICTMA) edited book chapters & 5 \\
Learning and Instruction & 3 \\
Mathematical Thinking and Learning & 3 \\
Educational Studies in Mathematics & 2 \\
Mathematics Education Research Journal & 2 \\
Mathematics Education Research Group of Australasia Annual Conference & 2 \\
ZDM & 2 \\
Mathematical Modelling in Education Research and Practice book & 2 \\
Journal for Research in Mathematics Education & 1 \\
Journal of Mathematical Modelling and Application & 1 \\
Cognition and Instruction & 1 \\
American Educational Research Association Annual meeting & 1 \\
Boletim de Educação Matemática & 1 \\
Journal of Mathematical Behaviour & 1 \\
Journal Internacional de Estudos em Educação Matemática & 1 \\
East Asia Regional Conference on Mathematics Education & \\
\hline
\end{tabular}

TABle 3: Number of articles per five-year time period.

\begin{tabular}{lc}
\hline Period & Number of articles \\
\hline $1991-1995$ & 2 \\
$1996-2000$ & 6 \\
$2001-2005$ & 4 \\
$2006-2010$ & 7 \\
$2011-2015$ & 10 \\
\hline
\end{tabular}

at the edited books arising from the conferences of the International Community of Teachers of Mathematical Modelling and Applications (ICTMA). Specific journals were looked at which included the Journal of Mathematical Modelling and Application, Teaching Mathematics and its Applications, and Educational Studies in Mathematics. Special issues of journals that focused on mathematical modelling were also investigated which included two issues of ZDM from 2006, one issue of Mathematical Thinking and Learning from 2003, and one issue of the Journal of Mathematics Education at Teachers College in 2013. The general literature search went back to 1970 using Google Scholar and included terms such as mathematical modelling and model-eliciting activities with elementary grades, primary school, early ages, and young learners.

This study followed the method of Diaz and Cox's [16] study that summarized engineering education articles. All studies on elementary grades mathematical modelling that also meet the essential elements of mathematical modelling were summarized using the categories of content of mathematical modelling intervention, assessment data collected, unit of analysis studied, population, and effectiveness. There were 29 publications identified. Table 2 describes the number of articles identified from each journal, book, or conference.

Table 3 shows the number of articles in 5 -year periods. An increase is observed in the last decade, mostly from
ICTMA book chapters and research by Lyn English, who by far is the author with the most publications on elementary mathematical modelling.

\section{Results}

4.1. Content of Mathematical Modelling Intervention. The content of the mathematical modelling activities fell into three main categories: ratios and proportional relationships, number and operations, and measurement and data/statistics. Three studies' activities had connections to proportionality $[6,17,18]$. Fifth-grade students from Belgium experienced a two-and-a-half-week unit on realistic modelling. Part of the time was spent on proportionality, in which students had to determine whether using a proportional strategy was appropriate. For example, using a 100-meter race time to predict an athlete's 400 -meter race time would not be appropriate because it would be difficult for an athlete to keep a 100-meter race pace for 400 meters [18]. Australian students used informal notions of proportions as part of a three-year study that involved MEAs, model-exploration activities in which students apply their model to a similarly structured problem with a different context, and modeladaptation problems in which students need to adapt their model to solve a new problem. The activity discussed in the article has students develop a consumer guide to help people choose the best snack chip based on criteria the students selected, for example, cost and taste [6]. In another study students are given choices of materials and costs to determine the best choice for covering the floor of a room [17]. In a butter beans MEA students are given tables of data displaying the weight of butter beans over time and must decide which condition is better. This activity can have connections to rates [19].

In the number and operations category the content included arithmetic operations (e.g., [8]), estimation [20], algebraic tasks that allow for generalizations [21], union or 
separation of two sets [18], averages (e.g., [22]), and exchange rates [23]. There were five studies that involved arithmetic operations with three of the studies using the same ten pairs of word problems that were first used in Verschaffel et al. [8]. For these word problems the first pair could be solved in a straightforward way while the second could not be if the real world situation was seriously taken into account. For example, a first straightforward question asks if a man cuts a clothesline of 12 meters into pieces of 1.5 meters each, how many pieces does he get? The second question in this pair requires some assumptions and approximations to be made. A man wants to have rope long enough to stretch between two poles 12 meters apart, but he has only pieces of 1.5-meter long rope. How many of these pieces would he need to tie together to stretch between the poles? [24]. Six studies had activities with connections to the concept of average $[6,8$, 19, 22, 25, 26]. English [22] had two classes of fourth-grade students who completed two MEAs in which they selected the Australian swimming teams for the Commonwealth Games given swimming times at different meets. MEAs used in Lesh et al. [27] promote students to work on patterns of information, linked with using numbers to represent mathematical objects (like locations or paths). There was one study done with geometry content [28]. In the Kawakami et al.s [29] study the content of activities is concretely working with three- and two-dimensional shapes and figures.

The largest amount of content connections was in the measurement and data/statistics category. The content included interpreting and dealing with multiple tables of data (e.g., [30-32]), quantifying qualitative data [6, 33], operationally defining constructs [6], exploring relationships and trends (e.g., [34]), representing and structuring findings/data in visual and text forms (e.g., $[35,36])$, selecting, ranking, and aggregating data (e.g., [33]), weighted ranks (e.g., [30]), sampling [6], identifying variation in data $[34,37,38]$, using an optimization model that uses a two-dimensional coordinate grid [39], area [17], developing a survey and collecting data [35,40], volume measurement [28], and simple randomization distribution to test a hypothesis about the nature of ESP [40].

4.2. Assessment Data Collected. The studies were mostly qualitative with typical data collected from audio and video recordings, student work, and researcher field notes. MEAs were the most used approach to introduce modelling. Only a few studies used interviews. As mentioned above there were three studies that used the same ten paired word problems $[8,25,26]$. The second set of ten problems that could not be answered in a straightforward manner were scored with a code of expected answer (not dealing with the real world), technical error, realistic answer, no answer, and other answer. Petrosino et al. [38] used a seven-item test to assess graphical interpretation and statistical reasoning developed in part from National Assessment of Educational Progress (NAEP) items.

An experimental study was conducted that looked at the effects of an experimental realistic modelling program [18]. One experimental class and two control classes completed a pre-post test while the treatment group also completed a retention test one month after the posttest. The test consisted of ten items in five pairs of nonstandard modelling problems. The first problem in the pair was similar to the problems the students solved in the experimental classes while the second problem in the pair was the same structure but a different context. The test also consisted of five other straightforward word problems. The test questions were similar to those used by Verschaffel et al. [8].

Another experimental study investigated the effects of a 4-month program on solving mathematics application problems in regard to ability to solve mathematics application problems, beliefs, and standardized mathematics test scores. As part of the program students were taught heuristics for solving problems such as draw a picture, make a table, look for patterns, and simplify the numbers [41].

The Verschaffel et al.'s [41] study had the experimental and control classes completed a pre- and posttest and a retention test. The test had ten nonroutine tasks that were scored as correct, wrong, technical errors, or no answer. A self-made Likert questionnaire was used to assess students' beliefs about the teaching and learning of mathematical word-problem solving. In order to get a better insight into the qualitative changes in students' problem-solving processes as a consequence of the treatment, three pairs of students (one pair of high ability, one pair of medium ability, and one pair of low ability) from each of the four experimental classes were videotaped solving nonroutine problems. The videotapes were analyzed for the use of the eight heuristics taught in the program, the frequency of four valuable metacognitive activities (orientation, planning, monitoring, and evaluation), and the final result of the problem-solving process (correct, wrong, technical error, or no answer). Teachers in the experimental group were also observed four times and scored based on ten categories of teacher activities that were considered essential for the successful implementation of the experimental learning environment.

4.3. Population. The studies were done in a range of countries with ten of the studies occurring in Australia: Australia (10), US (6), Belgium (3), Japan (3), Brazil (2), Singapore (1), Portugal (1), Germany (1), Ireland (1), and Switzerland (1). While the studies did provide some demographic information, the analysis done in the studies did not focus specifically on this. One of the studies was conducted in the inner city [34], four in a suburban location $[19,26,35,40]$, and five with middle socioeconomic status students [8, 18, 22, 34, 37, 42]. The studies covered a good range of ages. One study was done with high achieving students [32].

Considerations for the teachers in the studies were mentioned in four of the studies in which the teachers received professional development on implementing mathematical modelling [19, 30, 33, 35]. A quality example of this is how English [30] employed a multilevel teaching experiment [43] in her three-year longitudinal study of four classes of 3rd grade students. At the first level students create models in their work. At the second and third level the teachers work with the researcher in designing and implementing the modelling problems. The modelling activities challenge the teachers as they consider the mathematical ideas that students 
might use and the best ways to respond to students' ideas. Researchers make sense of both the students' models and the teachers implementation of the modelling activities.

4.4. Units of Analysis. There are three main units of analysis for the studies: representational and conceptual competence, models created, and student beliefs. Each of these will be described in more detail below.

\subsection{Effectiveness}

4.5.1. Representational and Conceptual Competence. Representational and conceptual competence involves students developing fluency in working with different representations to develop their conceptual competence or understanding through modelling (e.g., $[6,22])$. The studies showed that representational and conceptual competence increases over time as students have more experience with modelling. Three studies demonstrated that if students have limited experiences with mathematical modelling they may not take into account the real world situation appropriately $[8,25,26]$. In the studies with fourth- and fifth-grade students done in Switzerland, Belgium, and Japan all students completed ten pairs of word problems with the first pair being a straightforward word problem and the second a nonroutine modelling problem. Students performed poorly on the modelling problems and solved them in a straightforward manner. It was only when the teachers in Switzerland told the students specifically to think about if there is sufficient information to get an answer and also to consider what additional information would be needed did the percentage of students responding appropriately increase to a modest fifty percent. In all three studies students did not have prior experience with mathematical modelling.

Using similar problems to these studies as a pre-post test, Verschaffel and De Corte [18] did an experimental study and found the two-and-a-half-week modelling treatment group to do statistically better on the posttest. Like the three studies above, both groups of students on the pretest did not appropriately take into account the real world situations. In a study that used younger students 1st- and 2nd-grade students had difficulty with the idea of creating a model. The task was for students to guess the grade level of student produced drawings. The 1st and 2 nd graders came up with systems of attributes that described categories but failed to use these rules as a model to guide classification. Fourth and fifth graders also completed the task and were able to use their category systems as rules that sent drawings into fixed categories [37].

Students can have developing conceptual understanding before instruction by participating in modelling activities. In an Australian study with seven 4th-grade classes where students completed two MEAs, English [22] found that students developed concepts that were far more advanced than what would have been taught in a traditional classroom. In the MEAs students were asked to select swimmers for the Olympic and Common Wealth Games. The content the students worked with included ranking and aggregating data, calculating and ranking means, and creating and working with weighted scores. In another Australian study done with MEAs over a six-month period, suburban 3rd-grade students were able to interpret and work with mathematical information, identify trends and patterns in data, represent their mathematical ideas in different formats, and communicate and justify their mathematical ideas. The MEAs involved studying animals, investigating growing conditions of beans, a paper airplane contest, and creating a survey about chocolate consumption. The students found the activities enjoyable but challenging [35]. A study with four classes of 3rd-grade suburban students in Australia with MEAs found the emergence of important ideas that students had not experienced in class such as rate of change, aggregating, and averaging. The students also developed facility in interpreting and working with tables of data [19].

In a study with one elementary student Cyrino and Oliveira [21] found that the student was able to think algebraically before being subject to explicit teaching of algebra. This study involved a directed interview in which the student was asked to specifically explain their thinking while solving a modelling task. A finding of a study done with thirtysix fourth-grade students who completed two modelling activities was that the students were able to link different representations and began to understand the meaning of mathematical symbols [23].

There is research support that students can do better at mathematics in general when mathematical modelling is integrated in the elementary classroom. Using an pretestposttest-retention test experimental design, Verschaffel et al. [41] had four classes of 5th graders in a modelling treatment group and seven control classes. After receiving modelling instruction with a specific focus on problemsolving heuristics the treatment group did statistically better on the posttest and retention test on mathematical modelling. The treatment group also had a medium significant effect size on a mathematics standardized achievement test compared to the control group. In a three-year longitudinal study English [6] found that MEAs enabled students' mathematical understanding to develop in multiple ways when compared to the traditional classroom problem posing. The students were able to create complex mathematical processes and constructs. Adding a rationale for why students may do better when mathematical modelling is integrated in a class Mulligan [32] found that a greater emphasis on pattern and structure in the early years can contribute significantly to students' development of representational competence.

When using MEAs with kindergarten through second graders Lesh et al. [27] noted several key points for implementation: (a) the importance of focusing on conceptual knowledge as well as factual and procedural knowledge; (b) the importance of focusing on a small number of "big ideas"; (c) the importance of focusing on usefulness outside of school; (d) the importance of focusing on higher-order processes such as modelling; and (e) the importance of focusing on research-based learning progressions.

4.5.2. Models Created. Across different studies it was found that elementary students can successfully participate in mathematical modelling $[17,20,30,33,39,42,44]$. With a modelling activity focused on determining what are important 
factors in buying a pair of sneakers, students used multiple interpretations and approaches and developed mathematics content [44]. While doing a Fermi problem, which requires estimation of large quantities, most third- to fourth-grade German students did not develop and implement a solution plan, but still in most cases modelling cycles led to highly appropriate solutions [20].

Students develop a range of strategies while being engaged in mathematical modelling [29-31, 33, 39, 42, 44]. In the team ranking MEA in which students need to rank the top five teams out of twelve, students had three primary criteria that were evident in the responses: (a) greatest number of wins, (b) greatest difference between wins and losses, and (c) team with the greatest ratio of wins to losses. In a modelling unit based on the theme of looking after our environment students created a broad range of models in organizing, structuring, and representing data. The students also identified a wide range of attributes in their process of sorting a predetermined set of items that might be in a messy room such as a ribbon, shoe, toy, or dog bone [42]. In another study, students developed six different types of models that included ranking and aggregating data and weighted scores in a problem of where the best place to have a settlement in Australia is in 1788 [33]. English [31] found that the realistic context of the modelling activities can sometimes help students develop a model and at times it can also be an obstacle. It was also seen in the study that children can interpret and investigate meaningful phenomena and identify complex attributes while building models. This is support that the elementary grades curriculum should include modelling.

4.5.3. Student Beliefs. There was one experimental study that investigated student beliefs with fifth-grade students in Belgium. The treatment group received twenty lessons total on solving math application problems over a four-month span. Beliefs were measured using a Likert survey with two scales. One was on pleasure and persistence in solving word problems and the other was on whether there was one right way to solve problems or if different paths could be taken. The treatment group was statistically significantly higher than the control group on the beliefs items at the conclusion of the study.

\section{Discussion and Concluding Points}

This paper summarized what is known about mathematical modelling at the elementary school level. While mathematical modelling traditionally has been confined to the secondary school level [22] due to its perceived difficulty, the studies here have shown that elementary students are capable of participating in mathematical modelling and benefit from it. Mathematical modelling done in the studies was often interdisciplinary integrating English language arts, history, or STEM concepts. This is a great benefit of mathematical modelling in the elementary grades and can be used as a buy-in to have mathematical modelling implemented more frequently.

There is a great opportunity for research to be done with mathematical modelling in the elementary grades as more countries' standards documents emphasize on mathematical modelling. Germany includes mathematical modelling as one of six compulsory competencies [45]. In the United States, mathematical modelling is one of the eight Standards for Mathematical Practice [46]. Australia has mathematical modelling as part of the concepts and techniques that students should know in the National Mathematics Curriculum [47]. As the standards are implemented the number of studies should increase and the number of articles per five-year period displayed in Table 3 shows that this is starting to take place.

For representational and conceptual competence future research can expand on the content that has been studied. The content of geometry, fractions, place value, decimals, and equations and expressions can be explored as to how modelling can enable students to develop conceptual understanding through different representations. This can be done by using a modelling treatment group and a control group to further document the effectiveness of mathematical modelling. The modelling treatment group can use modelling as a formative assessment or supplement to normal teaching to motivate, engage, and activate students' prior knowledge for the mathematics that they will learn.

For the unit of analysis, models created, a key question that remains to be answered is investigating the differences between students' individual ability and group ability in mathematical modelling. For the studies done in this unit of analysis all work was done in groups and reported based on the groups' models created. Research is needed on how to reliably assess individual contributions within mathematical modelling group work. One idea that can be explored further in this regard is to have students individually develop solutions to a mathematical modelling task before coming together and developing a final group model [48].

Only one study was done on student beliefs, but this is an important construct as beliefs are the best indicators of the decisions that individuals make throughout their lives [49]. Future research can focus on determining what are the best realistic contexts and modelling problems to ensure that students enjoy mathematics and see it as real life and applicable.

As more studies are done with mathematical modelling at the elementary level what is studied can be expanded. Modelling competencies are an important concept that have been researched at the secondary level (e.g., [50-52]) that can be expanded to the elementary level. Modelling competencies involve understanding the realistic problem and setting up a model based on reality, setting up a mathematical model from the real world, solving mathematical questions within a mathematical model, interpreting mathematical results in a real solution, and validating a solution, metacognition, effective communication and argumentation, and positive attitudes toward real world application problems [53]. English [34, 42] has looked at this in part with her investigation of students' metarepresentational competence which is students' explicit recognition of why they represented their data/model in the way they did.

Students' modelling processes and how they can improve over time can also be investigated further. Experience with 
the modelling process helps students improve, but more research can focus on the best way for elementary students to become familiar, comfortable, and adept with the modelling process. Two modelling processes that appear frequently in the literature can be used or adapted to be focused on with elementary students: Blum and LeiB's [12] modelling process and Lesh and Doerr's [13] four-step modelling process of description, manipulation, prediction, and verification. Blum and Borromeo Ferri [45] have also suggested a four-step modelling process that they have found useful for students in their grant projects that entails (1) understanding the task, (2) establishing a model, (3) using mathematics, and (4) explaining the results.

Teaching mathematical modelling can be difficult for teachers and studies should take this into consideration. This is due to the fact that when students are engaged in modelling activities, teachers are likely to encounter substantial diversity in thinking [54]. This requires teachers to listen to students, respond with useful questions, and help students make connections to other mathematical ideas. This is what Shulman [55] has called pedagogical content knowledge. Hill et al. [56] have further developed this construct by breaking it into teachers' knowledge of content and students, knowledge of content and teaching, and knowledge of curriculum. Teachers' knowledge of content and students is intertwined with how students think about, know, or learn particular content. Teachers' knowledge of content and teaching is knowing what misconceptions that students are likely to have, what strategies they will use, and how to respond to them effectively. In four of the studies professional development was provided for the teachers [19, 30, 33, 35], which should be included in more research to help teachers develop their pedagogical content knowledge. Many of the articles discussed in this paper can be used as a part of professional development because the articles described or provided the modelling curriculum and students' range of ideas or concepts developed from the activities (e.g.) [30, 33, 44]). The one main missing piece is questions that teachers can ask and how they can respond appropriately to students' models to help them further develop their mathematical concepts.

The findings of this paper have shown that mathematical modelling research in the elementary grades is in the early stages. It has been noted that mathematical modelling has been implemented sparingly by teachers [57, 58]. Teacher training is required for elementary teachers as a barrier to large-scale implementation of mathematical modelling is limited amounts of professional development [59]. This is especially important for the elementary grades as many elementary teachers are uncomfortable with teaching mathematics [60]. The focus on mathematical modelling internationally should only increase though as the PISA mathematics framework describes mathematical literacy with many connections to mathematical modelling [61].

Mathematical modelling needs to begin in the elementary grades [31] and the studies discussed here have shown that elementary students are capable of effectively participating in mathematical modelling and benefit from this approach. Model-eliciting activities were used often in the studies and have a solid research base for their structure and implementation. More research can be done on developing, implementing, and assessing MEAs in the elementary grades on a wider range of mathematical content. Future research can also focus on expanding the units of analysis that are studied including focusing more on student beliefs, modelling competencies, and how students progress through modelling processes in the same way resources, heuristics, control, and beliefs have been studied as key aspects in mathematics problem solving [62].

\section{Competing Interests}

The authors declare that they have no competing interests.

\section{References}

[1] T. Ikeda and M. Stephens, "Three teaching principles for fostering students' thinking about modelling: an experimental teaching program for 9th grade students in Japan," Journal of Mathematical Modelling and Application, vol. 1, no. 2, pp. 49$59,2010$.

[2] J. P. Brown and I. Edwards, "Modelling tasks: insight into mathematical understanding," in Trends in Teaching and Learning of Mathematical Modelling, G. Kaiser, W. Blum, R. Ferri, and G. Stillman, Eds., pp. 187-197, Springer, New York, NY, USA, 2011.

[3] R. Lesh and G. Carmona, "Piagetian conceptual systems and models for mathematizing everyday experiences," in Beyond Constructivism: Models and Modeling Perspectives on Mathematics Problem Solving, Teaching, and Learning, R. Lesh and H. Doerr, Eds., pp. 71-96, Routledge, New York, NY, USA, 2003.

[4] G. Kaiser and B. Schwarz, "Mathematical modelling as bridge between school and university," $Z D M$, vol. 38, no. 2, pp. 196208, 2006.

[5] K. MaaB, "Modeling in class and the development of beliefs about the usefulness of Mathematics," in Modeling Students' Mathematical Modeling Competencies, R. Lesh, P. Galbraith, C. Haines, and A. Hurford, Eds., pp. 409-420, Springer, New York, NY, USA, 2010.

[6] L. D. English, "Mathematical modeling in the primary school: children's construction of a consumer guide," Educational Studies in Mathematics, vol. 63, no. 3, pp. 303-323, 2006.

[7] K. Karp, S. Bush, and B. Dougherty, "13 rules that expire," Teaching Children Mathematics, vol. 21, no. 1, pp. 18-25, 2014.

[8] L. Verschaffel, E. De Corte, and S. Lasure, "Realistic considerations in mathematical modeling of school arithmetic word problems," Learning and Instruction, vol. 4, no. 4, pp. 273-294, 1994.

[9] A. Schoenfeld, "Mathematical modeling, sense making, and the common core state standards," Journal of Mathematics Education at Teachers College, vol. 4, pp. 6-17, 2013.

[10] R. Lesh and H. M. Doerr, "Foundations of a models and modeling perspective on mathematics teaching, learning, and problem solving," in Beyond Constructivism, R. Lesh and H. Doerr, Eds., pp. 3-38, Lawrence Erlbaum Associates, Mahwah, NJ, USA, 2003.

[11] R. Lesh, G. Carmona, and T. Moore, "Six sigma learning gains and long term retention of understandings and attitudes related to models \& modeling," Mediterranean Journal for Research in Mathematics education, vol. 9, no. 1, pp. 19-54, 2009. 
[12] W. Blum and D. LeiB, "How do students and teachers deal with modelling problems," in Mathematical modelling: Education, Engineering and Economics, C. Haines, P. Galbraith, W. Blum, and S. Khan, Eds., pp. 222-231, Horwood, Chichester, UK, 2007.

[13] R. Lesh and H. M. Doerr, "In what ways does a models and modeling perspective move beyond constructivism?" in Beyond Constructivism, R. Lesh and H. Doerr, Eds., pp. 519-556, Lawrence Erlbaum Associates, Mahwah, NJ, USA, 2003.

[14] R. Lesh, M. Hoover, B. Hole, A. Kelly, and T. Post, "Principles for developing thought-revealing activities for students and teachers," in Research Design in Mathematics and Science Education, A. Kelly and R. Lesh, Eds., pp. 591-646, Lawrence Erlbaum and Associates, Mahwah, NJ, USA, 2000.

[15] A. Bryman, Social Research Methods, Oxford University Press, Oxford, UK, 2nd edition, 2004.

[16] N. V. Diaz and M. F. Cox, "An overview of the literature: research in p-12 engineering education," Advances in Engineering Education, vol. 3, no. 2, pp. 1-37, 2012.

[17] C. M. E. Chan, "Tracing primary 6 students model development within the mathematical modelling process," Journal of Mathematical Modelling and Application, vol. 1, no. 3, pp. 40-57, 2010.

[18] L. Verschaffel and E. De Corte, "Teaching realistic mathematical modeling in the elementary school: a teaching experiment with fifth graders," Journal for Research in Mathematics Education, vol. 28, no. 5, pp. 577-601, 1997.

[19] L. D. English and J. J. Watters, "Mathematical modelling in the early school years," Mathematics Education Research Journal, vol. 16, no. 3, pp. 58-79, 2005.

[20] A. Peter-Koop, "Fermi problems in primary mathematics classrooms: pupils' interactive modelling processes," in Mathematics Education for the Third Millenium: Towards 2010, pp. 454-461, 2004.

[21] M. C. C. T. Cyrino and H. M. Oliveira, "Pensamento algébrico ao longo do ensino básico em Portugal," Bolema: Boletim de Educação Matemática, vol. 24, no. 38, pp. 97-126, 2011.

[22] L. D. English, "Modeling with complex data in the primary school," in Modeling Students' Mathematical Modeling Competencies, R. Lesh, P. Galbraith, C. R. Haines, and A. Hurford, Eds., pp. 287-299, Springer, New York, NY, USA, 2010.

[23] L. M. W. de Almeida and E. Tortola, "Modelagem matemática no ensino fundamental: a linguagem de alunos como foco de análise," Jornal Internacional de Estudos em Educação Matemática, vol. 7, no. 1, 2015.

[24] B. Greer, "The mathematical modeling perspective on wor(l)d problems," The Journal of Mathematical Behavior, vol. 12, no. 3, pp. 239-250, 1993.

[25] K. Reusser and R. Stebler, "Every word problem has a solutionthe social rationality of mathematical modeling in schools," Learning and Instruction, vol. 7, no. 4, pp. 309-327, 1997.

[26] H. Yoshida, L. Verschaffel, and E. De Corte, "Realistic considerations in solving problematic word problems: do Japanese and Belgian children have the same difficulties?" Learning and Instruction, vol. 7, no. 4, pp. 329-338, 1997.

[27] R. Lesh, L. English, S. Sevis, and C. Riggs, "Modeling as a means for making powerful ideas accessible to children at an early age," in The SimCalc Vision and Contributions, S. J. Hegedus and J. Roschelle, Eds., Advances in Mathematics Education, pp. 419436, Springer, Amsterdam, The Netherlands, 2013.

[28] A. V. de Almeida, E. G. Souza, and L. B. de Souza, "Mathematical texts in a mathematical modelling learning environment in primary school," in Mathematical Modelling in Education Research and Practice, pp. 535-543, Springer, 2015.
[29] T. Kawakami, A. Saeki, and A. Matsuzaki, "How do students share and refine models through dual modelling teaching: the case of students who do not solve independently," in Mathematical Modelling in Education Research and Practice, pp. 195-206, Springer, 2015.

[30] L. D. English, "Promoting interdisciplinarity through mathematical modelling," ZDM-International Journal on Mathematics Education, vol. 41, no. 1-2, pp. 161-181, 2009.

[31] L. D. English, "Learning through modelling in the primary years," in Mathematical Modelling: From Theory to Practice, N. H. Lee and D. K. E. Ng, Eds., pp. 99-124, National Institute of Education, Singapore, 2015.

[32] J. Mulligan, "Moving beyond basic numeracy: data modeling in the early years of schooling," ZDM, vol. 47, no. 4, pp. 653-663, 2015.

[33] L. D. English, "Interdisciplinary modelling in the primary mathematics curriculum," in Proceedings of the 30th Mathematics Education Research Group of Australasia Annual Conference, J. Watson and K. Beswick, Eds., pp. 275-284, MERGA, Hobart, Ohio, USA, 2007.

[34] L. D. English, "Data modelling with first-grade students," Educational Studies in Mathematics, vol. 81, no. 1, pp. 15-30, 2012.

[35] J. Watters, L. English, and S. Mahoney, "Mathematical modeling in the elementary school," in Proceedings of the American Educational Research Association Annual Meeting, AERA, San Diego, Calif, USA, April 2004.

[36] T. Kawakami, "Enhancing young children's reasoning about data distribution through model creating and sharing," in Proceedings of the 7th ICMI-East Asia Regional Conference on Mathematics Education, Cebu City, Philippines, May 2015.

[37] R. Lehrer and L. Schauble, "Inventing data structures for representational purposes: elementary grade students' classification models," Mathematical Thinking and Learning, vol. 2, no. 1-2, pp. 51-74, 2000.

[38] A. Petrosino, R. Lehrer, and L. Schauble, "Structuring error and experimental variation as distribution in the fourth grade," Mathematical Thinking and Learning, vol. 5, no. 2-3, pp. 131-156, 2003.

[39] G. Carmona and S. Greenstein, "Investigating the relationship between the problem and the solver: who decides what math gets used?" in Modeling Students' Mathematical Modeling Competencies, R. Lesh, P. Galbraith, C. Haines, and A. Hurford, Eds., pp. 245-254, Springer, New York, NY, USA, 2010.

[40] R. Lehrer and T. Romberg, "Exploring children's data modeling," Cognition and Instruction, vol. 14, no. 1, pp. 69-108, 1996.

[41] L. Verschaffel, E. De Corte, S. Lasure, G. Van Vaerenbergh, H. Bogaerts, and E. Ratinckx, "Learning to solve mathematical application problems: a design experiment with fifth graders," Mathematical Thinking and Learning, vol. 1, no. 3, pp. 195-229, 2009.

[42] L. D. English, "Young children's early modelling with data," Mathematics Education Research Journal, vol. 22, no. 2, pp. 2447, 2010.

[43] R. Lesh and A. E. Kelly, "Multi-tiered teaching experiments," in Handbook of Research Design in Mathematics and Science Education, R. A. Lesh and A. Kelly, Eds., pp. 197-230, Lawrence Erlbaum Associates, Mahwah, NJ, USA, 2000.

[44] L. English, "Mathematical modelling with young learners," in Mathematical Modelling: A Way of Life ICTMA11, S. J. Lamon, W. A. Parker, and S. K. Houston, Eds., pp. 3-17, Horwood, Chichester, UK, 2003. 
[45] W. Blum and R. Borromeo Ferri, "Mathematical modelling: can it be taught and learnt?" Journal of Mathematical Modelling and Application, vol. 1, no. 1, pp. 45-58, 2009.

[46] Common Core State Standards Initiative, "Common core standards for mathematics," 2010, http://www.corestandards.org/ assets/CCSI_Math\%20Standards.pdf.

[47] Australian Curriculum, Assessment and Reporting Authority, 2015, http://www.australiancurriculum.edu.au/mathematics/ curriculum/f-10?layout=1.

[48] M. Stohlmann, C. Maiorca, and T. Olson, "Preservice secondary teachers' conceptions from a mathematical modeling activity and connections to the Common Core State Standards," The Mathematics Educator Journal, vol. 24, no. 1, pp. 21-43, 2015.

[49] M. F. Pajares, "Teachers' beliefs and educational research: cleaning up a messy construct," Review of Educational Research, vol. 62, no. 3, pp. 307-332, 1992.

[50] P. Biccard and D. C. J. Wessels, "Documenting the development of modelling competencies of grade 7 mathematics students," in Trends in Teaching and Learning of Mathematical Modelling, G. Kaiser, W. Blum, R. B. Ferri, and G. Stillman, Eds., vol. 1 of International Perspectives on the Teaching and Learning of Mathematical Modelling, pp. 375-383, Springer, New York, NY, USA, 2011.

[51] S. Grünewald, "The development of modelling competencies by year 9 students: effects of a modelling project," in Teaching Mathematical Modelling: Connecting to Research and Practice, G. A. Stillman, G. Kaiser, W. Blum, and J. P. Brown, Eds., International Perspectives on the Teaching and Learning of Mathematical Modelling, chapter 16, pp. 185-194, Springer, New York, NY, USA, 2013.

[52] K. Maaß, "Modelling in class: what do we want the students to learn?" in Mathematical Modelling: Education, Engineering and Economics, C. Haines, P. Galbraith, W. Blum, and S. Khan, Eds., pp. 63-78, Horwood Publishing, Chichester, UK, 2007.

[53] K. Maaß, "What are modelling competencies?" ZDM, vol. 38, no. 2, pp. 113-142, 2006.

[54] H. Doerr and D. Lesh, "Models and Modelling perspectives on teaching and learning mathematics in the twenty-first century," in Trends in Teaching and Learning of Mathematical Modelling, G. Kaiser, W. Blum, R. Ferri, and G. Stillman, Eds., pp. 247-268, Springer, New York, NY, USA, 2011.

[55] L. S. Shulman, "Those who understand: knowledge growth in teaching," Educational Researcher, vol. 15, no. 2, pp. 4-14, 1986.

[56] H. C. Hill, D. L. Ball, and S. G. Schilling, "Unpacking pedagogical content knowledge: conceptualizing and measuring teachers' topic-specific knowledge of students," Journal for Research in Mathematics Education, vol. 39, no. 4, pp. 372-400, 2008.

[57] K. E. D. Ng, "Initial perspectives of teacher professional development on mathematical modelling in Singapore: a framework for facilitation," in Teaching Mathematical Modelling: Connecting to Research and Practice, G. Stillman, G. Kaiser, W. Blum, and J. Brown, Eds., International Perspectives on the Teaching and Learning of Mathematical Modelling, pp. 427436, Springer, New York, NY, USA, 2013.

[58] M. Winter and H. Venkat, "Pre-service teacher learning for mathematical modelling," in Teaching Mathematical Modelling: Connecting to Research and Practice, G. A. Stillman, G. Kaiser, W. Blum, and J. P. Brown, Eds., International Perspectives on the Teaching and Learning of Mathematical Modelling, pp. 395404, Springer, New York, NY, USA, 2013.
[59] H. Burkhardt, "Modelling in mathematics classrooms: reflections on past developments and the future," $Z D M$, vol. 38, no. 2, pp. 178-195, 2006.

[60] D. L. Ball, S. T. Lubienski, and D. Mewborn, "Research on teaching mathematics: the unsolved problem of teachers' mathematical knowledge," in Handbook on Research in Teaching, V. Richardson, Ed., pp. 180-194, Macmillan, New York, NY, USA, 4th edition, 2001.

[61] OECD, "Mathematics framework," in PISA 2012 Assessment and Analytical Framework: Mathematics, Reading, Science, Problem Solving and Financial Literacy, OECD Publishing, 2013.

[62] A. Schoenfeld, Mathematical Problem Solving, Academic Press, New York, NY, USA, 1985. 


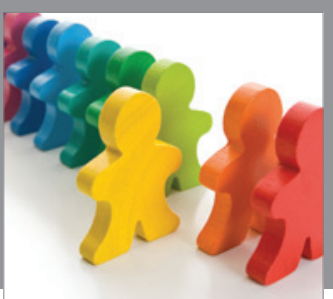

Autism

Research and Treatment
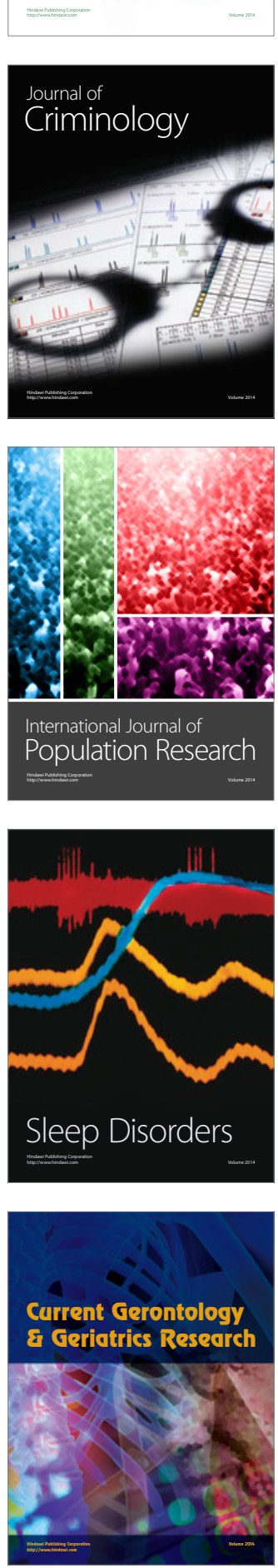

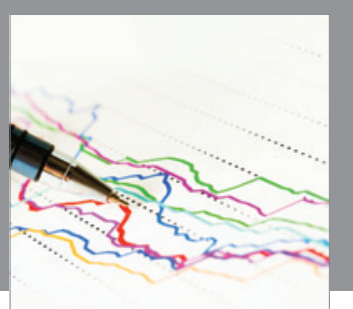

Economics

Research International
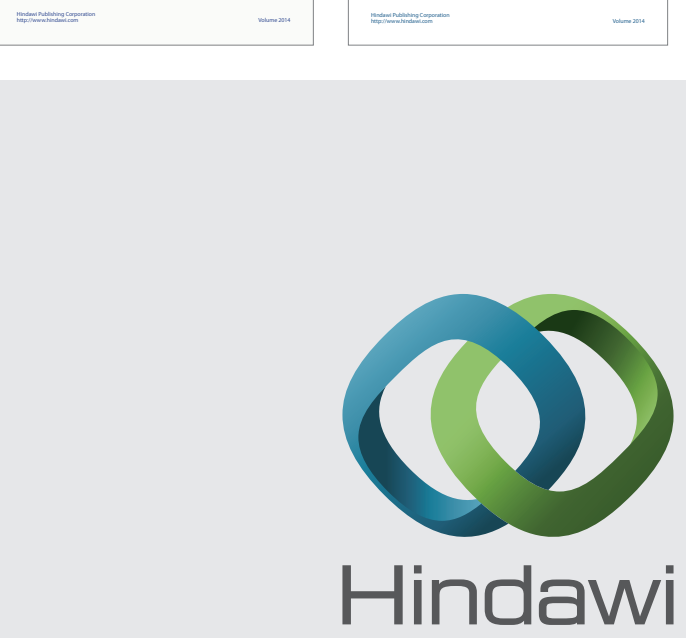

Submit your manuscripts at

http://www.hindawi.com
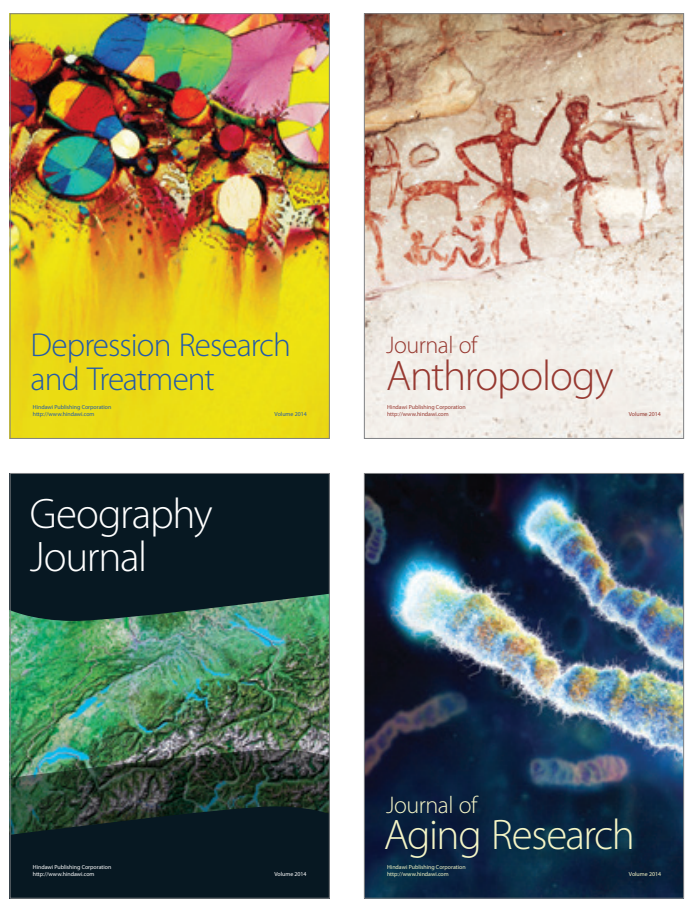
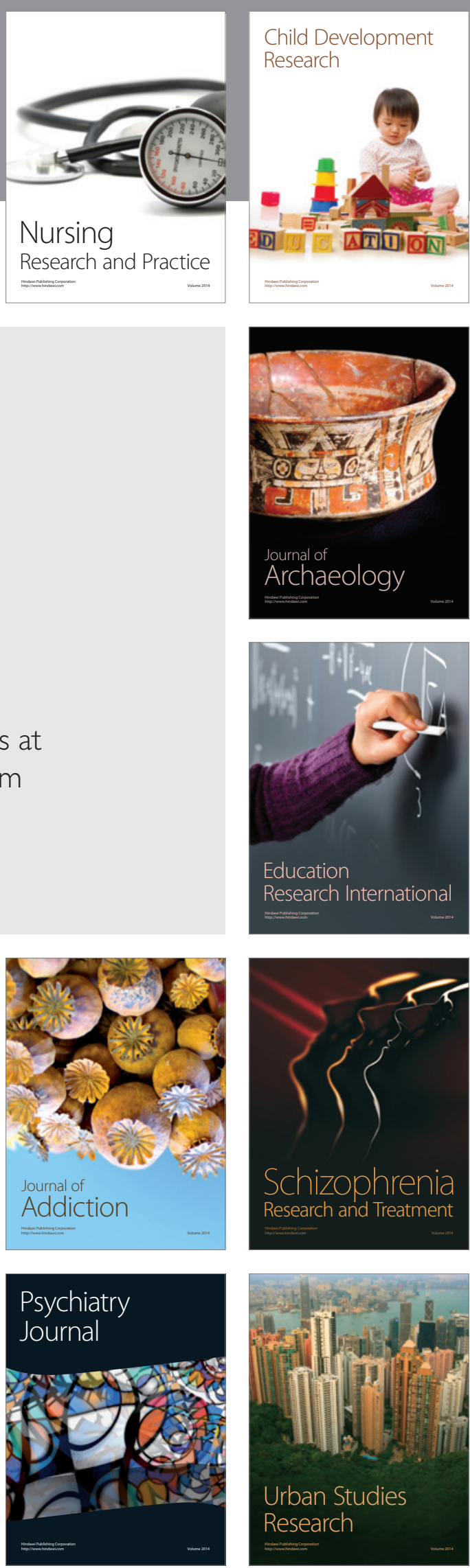